\title{
Presence of air in the hepatic portal system in association with umbilical venous catheter malposition*
}

\author{
Presença de ar no sistema porta hepático associada a cateter umbilical venoso mal posicionado
}

Beatriz Regina Alvares ${ }^{1}$, Mônica Carvalho Sanchez Stopiglia², Maria Aparecida Mezzacappa ${ }^{3}$

Alvares BR, Stopiglia MCS, Mezzacappa MA. Presence of air in the hepatic portal system in association with umbilical venous catheter malposition. Radiol Bras. 2014 Jan/Fev;47(1):49-50.

Abstract The authors report a case of umbilical venous catheter malposition with air in the portal venous system in a preterm neonate. Initially, the hypothesis of necrotizing enterocolitis was considered, but the newborn progressed with no finding of disease and the air disappeared at follow-up radiography. The differential diagnosis of such a finding can avoid unnecessary clinical treatments.

Keywords: Umbilical venous catheter; Newborn; Portal air; Necrotizing enterocolitis; Radiological study.

Resu mo Apresentamos um caso relacionado a cateter umbilical venoso mal posicionado, associado à presença de ar no sistema portal, em um recém-nascido prematuro. A hipótese de enterocolite necrosante foi considerada inicialmente, porém o recém-nascido evoluiu sem achados da doença, tendo o ar desaparecido em radiografia de controle. 0 diagnóstico diferencial deste achado evita condutas clínicas desnecessárias.

Unitermos: Cateter umbilical venoso; Recém-nascido; Ar portal; Enterocolite necrosante; Exame radiológico.

\section{INTRODUCTION}

Umbilical venous catheterization is a common procedure in the management of preterm neonates, and is considered a swift and reliable procedure ${ }^{(1)}$. However, its utilization is also associated with complications such as thrombosis, embolism, hemorrhages, heart arrhythmias, effusion, portal hypertension and sepsis ${ }^{(1-4)}$. In order to avoid such complications, it is important that the tip of the umbilical venous catheter (UVC) be located in the inferior vena cava, near the entrance of the right atrium ${ }^{(5)}$.

Chest and abdominal radiography is routinely performed in order to accurately identify the location of the UVC with basis on previously determined anatomical references ${ }^{(2-5)}$, and it is considered properly positioned as visualized at the right side of the T8 and T9 vertebral bodies, the anatomical location of the inferior vena cava, near the right atrium ${ }^{(5)}$. During the UVC insertion, particularly in cases where the tip is located near the portal vein, a small amount of air may inadvertently be inserted through the umbilical vein, and may migrate toward the portal system, being transiently visualized at follow-up radiography ${ }^{(3,4)}$.

* Study developed at Hospital da Mulher Prof. Dr. José Aristodemo Pinotti CAISM-Unicamp, Campinas, SP, Brazil.

1. PhD, Professor, Department of Radiology, Faculdade de Ciências Médicas da Universidade Estadual de Campinas (FCM-Unicamp), Campinas, SP, Brazil.

2. Master, Fisiotherapist at Hospital da Mulher Prof. Dr. José Aristodemo Pinotti - CAISM-Unicamp, Campinas, SP, Brazil.

3. PhD, Professor, Department of Pediatrics, Faculdade de Ciências Médicas da Universidade Estadual de Campinas (FCM-Unicamp), Campinas, SP, Brasil.

Mailing Address: Dra. Beatriz Regina Alvares. Rua Alberto de Salvo, 238, Distrito de Barão Geraldo. Campinas, SP, Brazil, 13084-759. E-mail: alvaresb@terra.com.br.

Received December 19, 2012. Accepted after revision June 5, 2013.
The present report describes a case related to inappropriate UVC positioning and inadvertent air insertion into the hepatic portal system in a preterm neonate. Initially, the hypothesis of necrotizing enterocolitis was considered because of the high risk posed by this condition in such an age group.

\section{CASE REPORT}

A male infant born at 32 weeks of gestation, weighting 1,160 grams was submitted to umbilical venous catheterization at 70 minutes of life. The tip of the UVC was radiologically identified at the right side of the T7-T8 vertebral bodies, above the correct location (T8-T9), then the catheter was tractioned approximately $1 \mathrm{~cm}$. At the fourth day of life, the neonate presented with bilious residuals, and plain chest and abdominal radiography (frontal view) was performed. The UVC tip was then visualized at the level of the T10 vertebral body in association with presence of air in the hepatic portal system (Figure 1), and the catheter was subsequently removed. The patient remained with bilious residuals and, after five hours, a new radiography was performed, demonstrating persistence of portal air (Figure 2) and mild distention of bowel loops, raising the hypothesis of necrotizing enterocolitis. A new radiography performed after six hours still demonstrated the presence of air, but at the subsequent radiological follow-up, at the fifth day of life, it had disappeared (Figure 3).

The neonate's clinical evolution and laboratory tests made it possible to rule out necrotizing enterocolitis. Based on the progression of the clinical and radiological condition, the final diagnosis was established as presence of air in the portal system due to umbilical venous catheter malposition at the occasion when it was tractioned. 


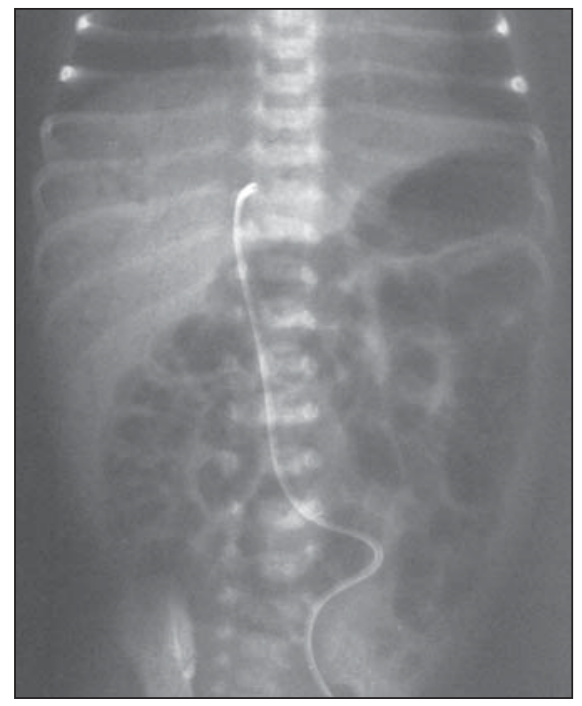

Figure 1. Umbilical venous catheter at the right side of the T10 vertebral body, at the level of the venous duct, next to the portal vein. The presence of air in the portal system can be observed on the liver projection image.

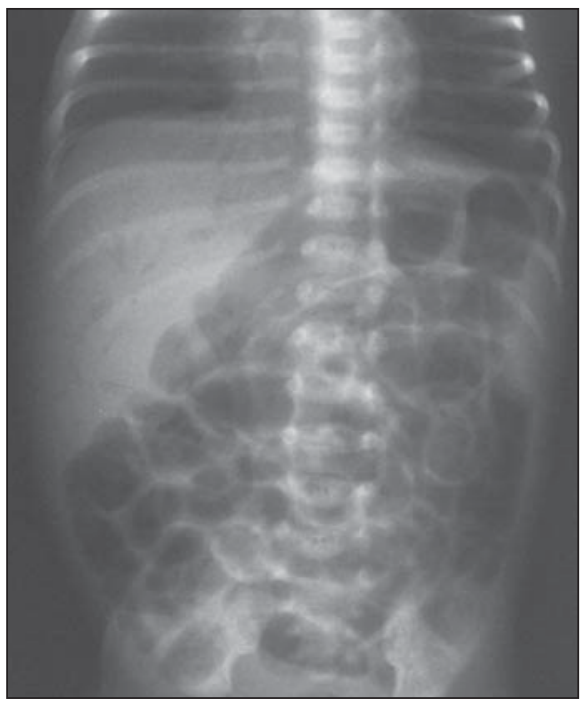

Figure 2. Radiography performed five hours after the catheter removal, still demonstrating the presence of air in the portal system.

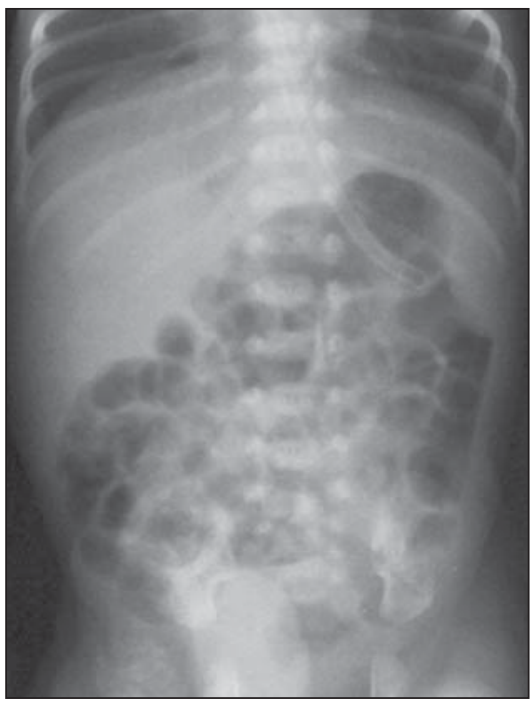

Figure 3. New radiography, performed approximately 20 hours after, demonstrating that the air in the portal system had disappeared.

\section{DISCUSSION}

The umbilical vein extends from the umbilicus to the hepatic region, where its name changes to umbilical recess, communicating with the portal veins branches and posteriorly discharging into the inferior vena cava through the venous duct ${ }^{(3)}$. As the umbilical venous catheter is inserted, particularly in those cases where it is located next to the portal vein, air may inadvertently enter and migrate toward the portal system, being occasionally found at follow-up radiography, and later disappearing ${ }^{(2,3)}$. In the present case, the tip of the umbilical catheter, after being pulled, was identified at the level of T10, next to the umbilical recess region, which may have caused the passage of air through the catheter into the portal system.

The radiological finding of air in the portal system, as associated with necrotizing enterocolitis, is almost always followed by intestinal pneumatosis ${ }^{(6,7)}$. In the present case, there was no evidence of pneumatosis intestinalis at radiography, but as the presence of portal air in neonates is associated with a high risk for necrotizing enterocolitis, such a diagnostic suspicion should be raised and ruled out ${ }^{(5-8)}$. Subsequent radiography demonstrated that the air had disappeared and clinical and laboratory findings did not confirm the necrotizing enterocolitis hypothesis.

In the final evaluation of the present case, one has concluded that portal air was inadvertently inserted as the catheter located next to the portal vein was tractioned.

\section{CONCLUSION}

In the absence of clinical, radiological and laboratory findings of necrotizing enterocolitis, the presence of air in the portal system can be attributed to umbilical catheter malposition and inadvertent penetration of air through the infusion lines. The differential diagnosis of such finding with necrotizing enterocolitis can avoid unnecessary clinical procedures.

\section{REFERENCES}

1. Butler-O'Hara M, Buzzard CJ, Reubens L, et al. A randomized trial comparing long-term and short-term use of umbilical venous catheters in premature infants with birth weights of less than 1251 grams. Pediatrics. 2006;118:e25-35.

2. Schlesinger AE, Braverman RM, DiPietro MA. Pictorial essay. Neonates and umbilical venous catheters: normal appearance, anomalous positions, complications, and potential aid to diagnosis. AJR Am J Roentgenol. 2003;180:1147-53.

3. Oestreich AE. Umbilical vein catheterization - appropriate and inappropriate placement. Pediatr Radiol. 2010;40:1941-9.

4. Verheij GH, Te Pas AB, Witlox RS, et al. Poor accuracy of methods currently used to determine umbilical catheter insertion length. Int J Pediatr. 2010;2010:873167.

5. Alvares BR, Pereira ICMR, Araújo Neto SA, et al. Achados normais no exame radiológico de tórax do recém-nascido. Radiol Bras. 2006; 39:435-40.

6. Alvares BR, Martins DL, Roma RL, et al. Aspectos radiológicos relevantes no diagnóstico da enterocolite necrosante e suas complicações. Radiol Bras. 2007;40:127-30.

7. Neu J, Walker WA. Necrotizing enterocolitis. N Engl J Med. 2011 ; 364:255-64.

8. Berman L, Moss RL. Necrotizing enterocolitis: an update. Semin Fetal Neonatal Med. 2011;16:145-50. 